\title{
Fabrication of a Sludge-Conditioning System for Processing Legacy Wastes from the Gunite and Associated Tanks
}

\author{
J. D. Randolph \\ B. E. Lewis \\ Oak Ridge National Laboratory \\ P.O. Box 2008 \\ Oak Ridge, Tennessee 37831 \\ J. R. Farmer \\ Lockheed Martin Energy Systems, Inc. \\ P.O. Box 2009 \\ Oak Ridge, Tennessee 37831 \\ M. A. Johnson \\ Tetra-Tech, Inc. \\ 800 Oak Ridge Turnpike \\ Oak Ridge, Tennessee 37830 \\ August 2000 \\ Prepared by the \\ OAK RIDGE NATIONAL LABORATORY \\ Oak Ridge, Tennessee 37831 \\ Managed by \\ UT-BATTELLE, LLC \\ For the \\ U.S. DEPARTMENT OF ENERGY \\ Under contract DE-AC05-OR22725

\footnotetext{
"The submitted manuscript has been authored by a contractor of the U.S. Government under contract No. DE-AC05-OR22725.

Accordingly, the U.S. Government retains a paid-up, nonexclusive, irrevocable, worldwide license to publish or reproduce the published form of this contribution, prepare derivative works, distribute copies to the public, and perform publicly and display publicly, or allow others to do so, for U.S. Government purposes."
} 


\begin{abstract}
The Sludge Conditioning System (SCS) for the Gunite and Associated Tanks (GAATs) is designed to receive, monitor, characterize and process legacy waste materials from the South Tank Farm tanks in preparation for final transfer of the wastes to the Melton Valley Storage Tanks (MVSTs), which are located at Oak Ridge National Laboratory. The SCS includes (1) a Primary Conditioning System (PCS) Enclosure for sampling and particle size classification, (2) a Solids Monitoring Test Loop (SMTL) for slurry characterization, (3) a Waste Transfer Pump to retrieve and transfer waste materials from GAAT consolidation tank W-9 to the MVSTs, (4) a PulsAir Mixing System to provide mixing of consolidated sludges for ease of retrieval, and (5) the interconnecting piping and valving. This report presents the design, fabrication, cost, and fabrication schedule information for the SCS.
\end{abstract}




\section{TABLE OF CONTENTS}

\begin{tabular}{|c|}
\hline 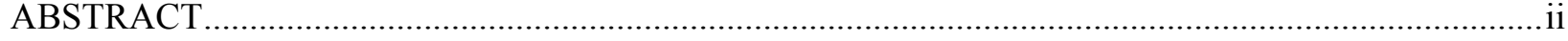 \\
\hline |TABLE OF CONTENTS \\
\hline 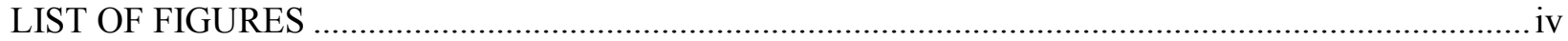 \\
\hline LIST OF TABLES \\
\hline ACRONYMS \\
\hline 1. SUMMARY ........... \\
\hline 2. INTRODUCTION \\
\hline B. SCS ......................... \\
\hline $3.1 \quad$ SMTL. \\
\hline 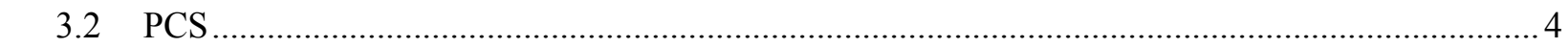 \\
\hline 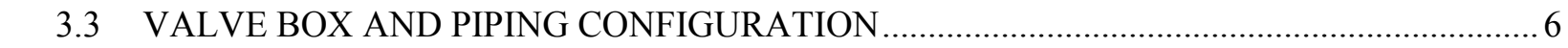 \\
\hline WTP \\
\hline 3.5 PAM \\
\hline 4. DESIGN AND FABRICATION \\
\hline 4.1 DESIGN ……....................... \\
\hline 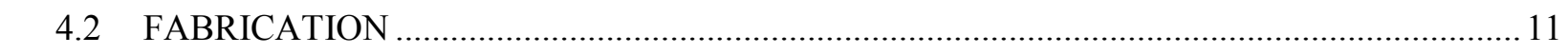 \\
\hline 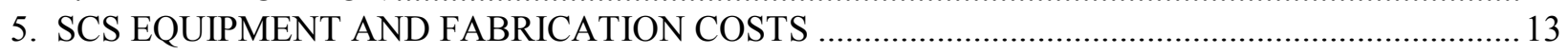 \\
\hline 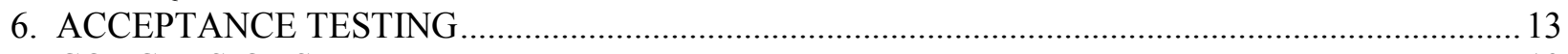 \\
\hline 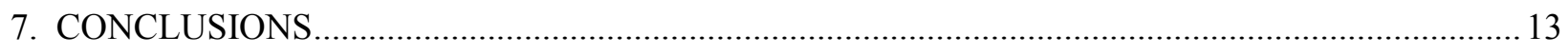 \\
\hline 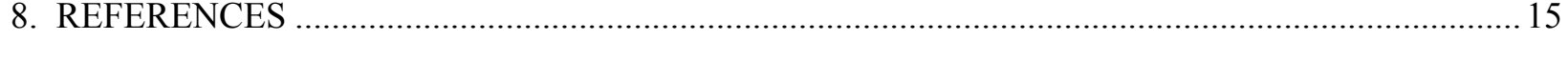 \\
\hline
\end{tabular}




\section{LIST OF FIGURES}

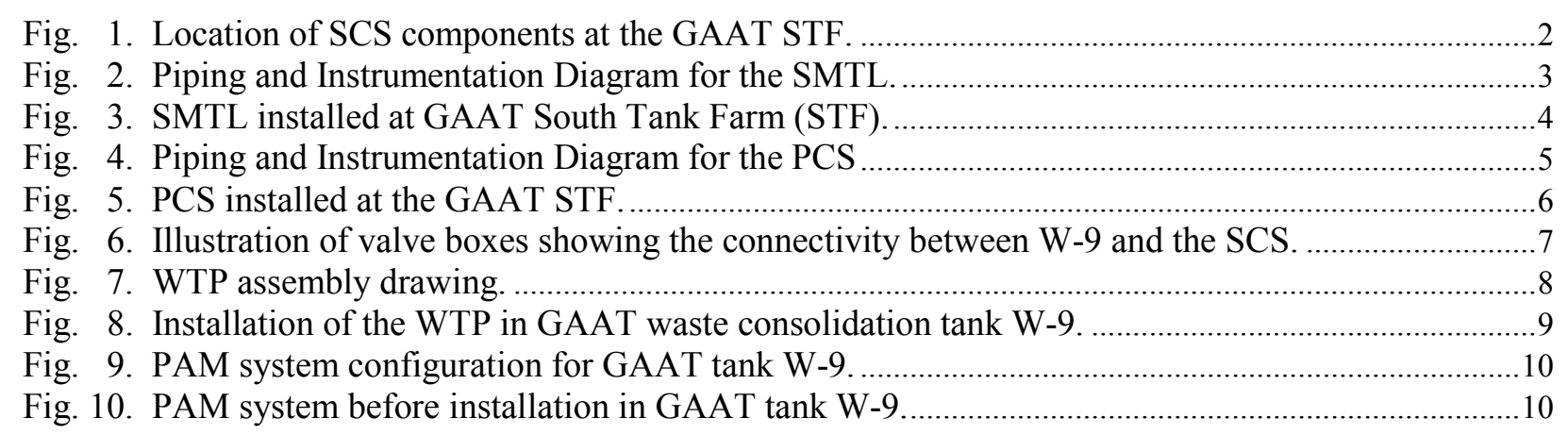

\section{LIST OF TABLES}

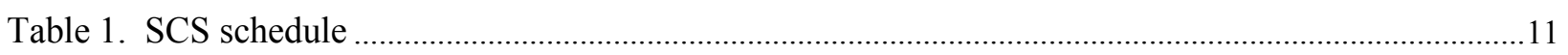

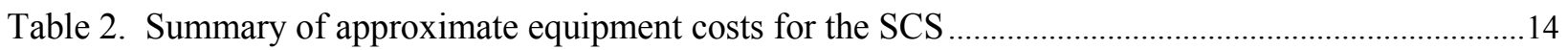




\section{ACRONYMS}

$\begin{array}{ll}\text { AFC } & \text { Alloy Fabrication Company } \\ \text { ASME } & \text { American Society of Mechanical Engineers } \\ \text { CERCLA } & \text { Comprehensive Environmental Response, Compensation, and Liability Act } \\ \text { DOE } & \text { Department of Energy } \\ \text { GAAT } & \text { Gunite and Associated Tank } \\ \text { HEPA } & \text { High efficiency particulate air } \\ \text { LMES } & \text { Lockheed Martin Energy Systems } \\ \text { LLLW } & \text { Low-level liquid waste } \\ \text { MVST } & \text { Melton Valley Storage Tank } \\ \text { ORNL } & \text { Oak Ridge National Laboratory } \\ \text { PAM } & \text { PulsAir mixer system } \\ \text { PCS } & \text { Primary conditioning system } \\ \text { ROV } & \text { Remotely operated valve } \\ \text { SCS } & \text { Sludge conditioning system } \\ \text { SMTL } & \text { Slurry monitoring test loop } \\ \text { STF } & \text { South tank farm } \\ \text { UST } & \text { Underground storage tank } \\ \text { WAC } & \text { Waste acceptance criteria } \\ \text { WaRTS } & \text { Waste retrieval and transfer system } \\ \text { WTP } & \text { Waste transfer pump }\end{array}$




\section{SUMMARY}

The Sludge Conditioning System (SCS) is designed to mobilize the easily suspendible particles, to classify the solids, monitor slurry characteristics, and to process slurried low-level liquid waste (LLLW) from the Gunite and Associated Tanks (GAATs) in preparation for the final transfer of the wastes to the Melton Valley Storage Tanks (MVSTs) site. The SCS is comprised of the Primary Conditioning System (PCS), the Slurry Monitoring Test Loop (SMTL), a Waste Transfer Pump (WTP), a PulsAir Mixer (PAM) system, and the associated piping system. The PCS primarily includes the solids classifiers and sampling devices. The SMTL includes the solids monitoring instruments and an additional sample station. The WTP is used to transfer the mobilized sludge material from tank W-9 through the SCS to the MVSTs. The PAM is used to mobilize the solids present in the GAAT waste-consolidation tank (W-9). The SCS components are primarily off-the-shelf equipment, which has been previously cold-tested at Oak Ridge National Laboratory (ORNL). ORNL and Lockheed Martin Energy Systems, Inc. (LMES) designed the piping schemes, which will permit the retrieved material to be either recirculated into the source tank or transferred to the MVSTs. This report outlines the design, equipment selection, itemized costs, fabrication schedule, and vendor information for the SCS.

\section{INTRODUCTION}

The GAAT environmental restoration project was implemented to retrieve legacy radiochemical sludge and supernatant wastes from eight, large inactive, underground storage tanks (USTs), which are located at ORNL. This activity is being conducted under the U.S. Environmental Protection Agency's (EPA's) Comprehensive Environmental Response, Compensation, and Liability Act (CERCLA) through an interim Record of Decision.

The operations team has completed the consolidation of waste from seven of the GAAT USTs into tank W-9. To promote ease of retrieval of the consolidated waste, a PAM system was deployed in Tank W-9 to ensure that the sludge particles are kept in suspension until they can be transferred to the MVSTs. The SCS has been designed, fabricated, and installed at the GAAT to prepare the waste for its final transfer through a 2-in. diam waste-transfer line to the MVSTs or alternate collection tanks.

This report provides a summary of the design and fabrication of the SCS for application to the U.S Department of Energy's (DOE's) ORNL GAAT waste retrieval project.

\section{SCS}

The SCS was designed to provide real-time monitoring of the slurries retrieved from the GAAT and to condition the slurry (i.e., solids particle size reduction), as necessary, to meet the waste acceptance criteria (WACs) for transport to the MVSTs. A drawing of the general arrangement of the major components of the SCS is shown in Fig. 1 The requirement for slurry conditioning is based upon ORNL's WAC for preventing the plugging of the Melton Valley transfer line since this is the primary LLLW transfer line for the entire ORNL site.

The SCS includes two equipment enclosures, a WTP, a PAM system, and necessary interconnecting piping and valves. The two enclosures are the SMTL and the PCS. The WTP is a submersible pump, which can be raised and lowered via a rigid mast. The PAM system uses pulses of pressurized air to mobilize the waste material present in the storage tank. 
The SCS is located at GAAT waste-consolidation tank W-9. The PAM system was installed in W-9 and used to suspend solids by continuously mixing the contents of the consolidation tank using pulses of pressurized air. The suspended slurry is transferred through the PCS and SMTL using the WTP. The SCS is designed to allow the transfer of slurry to the MVSTs or recirculation of the material back to the source tank (W-9). The slurry is initially recirculated through the PCS and SMTL and back into the source tank until the slurry-monitoring instruments in the SMTL indicate that the waste material meets or exceeds the WAC for waste transfers to the MVST. The SMTL is equipped with the necessary instruments for determining the particle sizes, solids content, and slurry density. The WAC for the MVST transfer primarily include the requirements that particle sizes be $\leq 100 \mu \mathrm{m}$ and with a solids content of $<10 \mathrm{wt} \%$. The sampling of the tank contents is also conducted to characterize the slurry and validate the information from the SMTL. The solids classifiers in the PCS are used to ensure that no solid particles larger than $100 \mu \mathrm{m}$ are allowed to enter the Melton Valley transfer line. Initially, the SCS design gave a placeholder for application of a grinder for supporting particle size reduction. However, based upon the results from sludge samples from tank W-9, it has been determined that a grinder will probably not be required. A pump will now occupy the space allocated for the grinder for the Waste Removal and Transfer System (WaRTS). WaRTS will be used for final retrieval of the waste remaining on the tank floor after the SCS transfers are completed.

ORNL-DWG 2000-5328

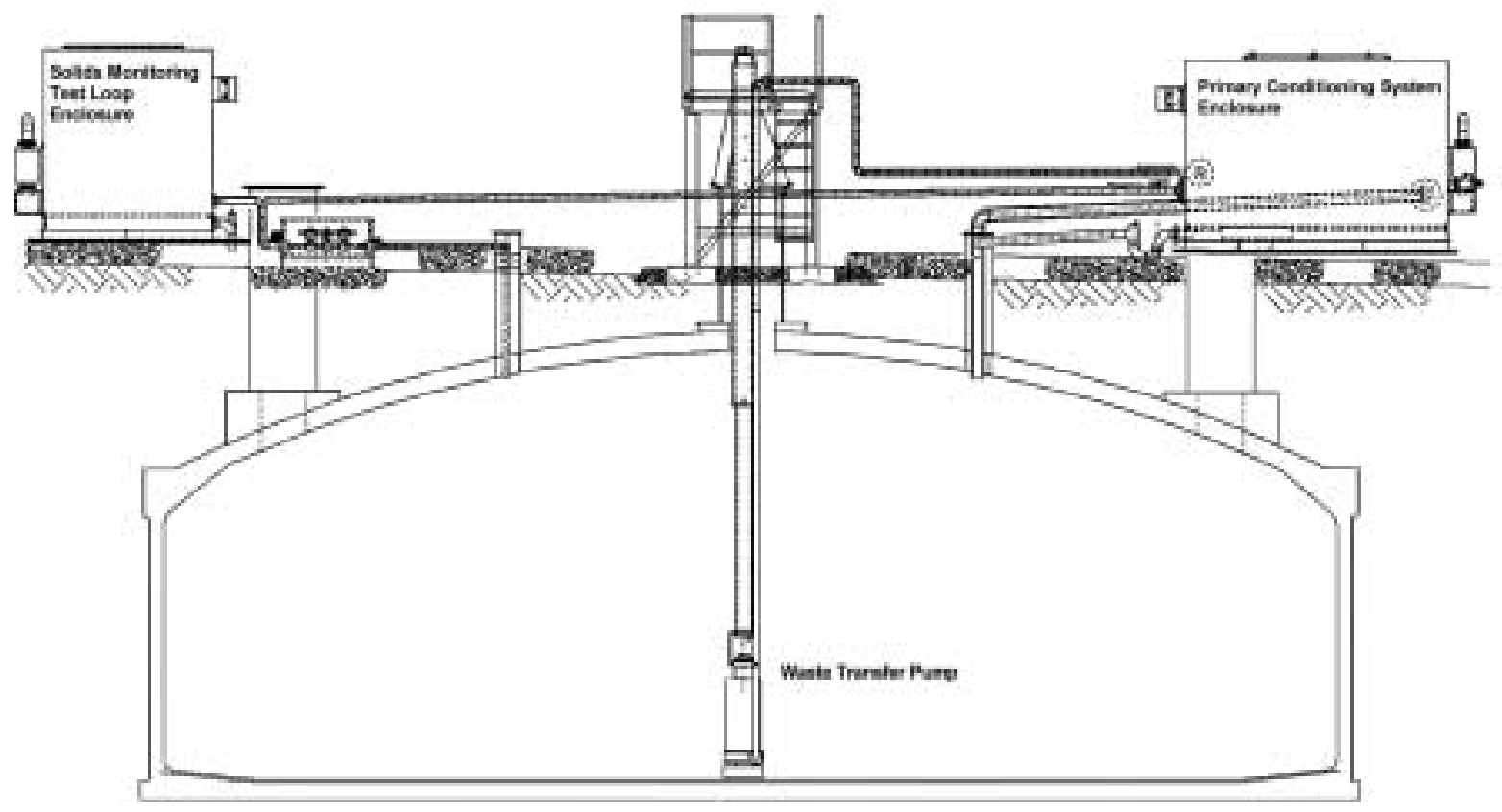

Fig. 1. Location of SCS components at the GAAT STF.

\subsection{SMTL}

The SMTL was designed for safe and remote operations with radioactive slurries. A piping and instrumentation diagram for the SMTL is shown in Fig. 2 The piping was constructed of 2 in.diam Carbon-steel pipe. All joints were welded - except for locations where instruments were installed. The instruments were equipped with spool pieces with $300-1 \mathrm{~b}$ flange connections to simplify operations, to promote ease of maintenance, and to meet the operational pressure 
requirements. The maximum allowable working pressure for the SMTL is $300 \mathrm{psig}$. The system is also configured to permit any or all of the slurry-monitoring equipment to be bypassed if necessary.

The SMTL is totally enclosed in a modified waste-drum-storage metal housing. Modifications to the housing included (1) replacement of the plywood-steel flooring with an all-steel floor, (2) installation of drains for diverting spillage back to tank W-9, (3) addition of spray nozzles for spill wash-down, (4) installation of a spill-prevention door seal, (5) installation of a temperature control system, and (6) connection of an off-gas ventilation duct to tank W-9's high efficiency particulate air (HEPA) filtration system.

ORNL-DWG 2000-5329

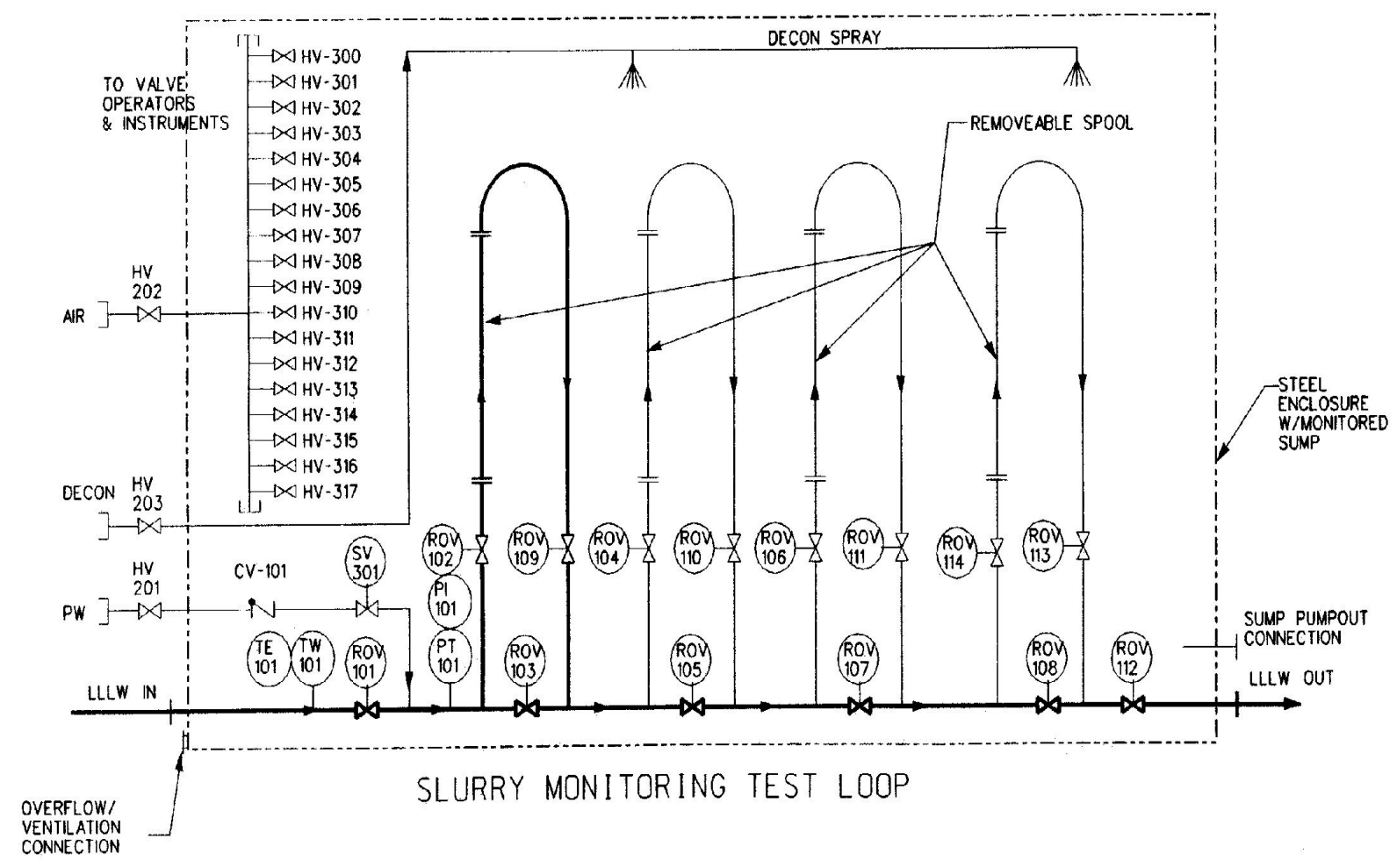

Fig. 2. Piping and Instrumentation Diagram for the SMTL.

The process instrumentation for the SMTL is comprised of an Endress-Hauser ${ }^{\mathrm{TM}}$ coriolis meter; a Lasentec ${ }^{\mathrm{TM}}$ particle-size distribution and/or count meter; an ultrasonic, suspended solids monitor, which was designed by Argonne National Laboratory; a pump power monitor; an Iso-Lok ${ }^{\mathrm{TM}}$ inline sampler; pressure and temperature sensors; and the necessary piping connections. The SMTL (Fig. 3) can be operated either remotely or locally depending on operational conditions and requirements. 


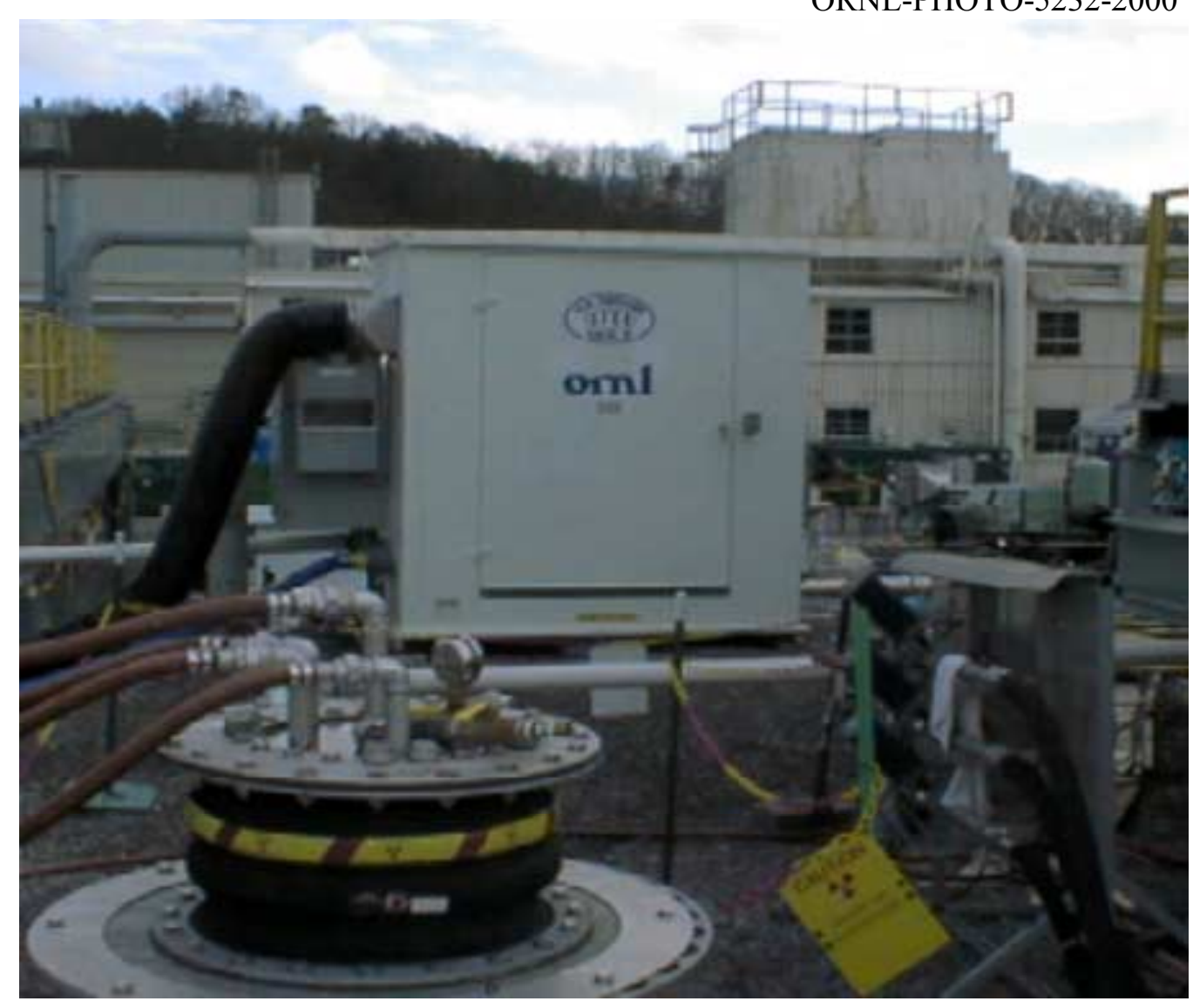

Fig. 3. SMTL installed at GAAT South Tank Farm (STF).

\section{2 $\quad$ PCS}

The PCS consists of a confinement enclosure, which houses the Orival ${ }^{\mathrm{TM}}$ solids classifiers, Bristol Iso-Lok samplers, a pressure transmitter, a process water flush connection, and the associated valves and piping. The enclosure has a HEPA-filtered inlet and ventilation connection with a back draft damper, which maintains a negative pressure by a connection to the tank W-9 off-gas system, which is a similar arrangement to that of the SMTL. The PCS also includes a sump, which drains back to tank W-9 (so as to collect any leaks that may occur from the process piping), lighting, freeze protection, and a wash-down capability to remove gross contamination from inside the enclosure in the event of a catastrophic leak. The equipment layout and piping flow diagram for the PCS are shown in Fig. 4 


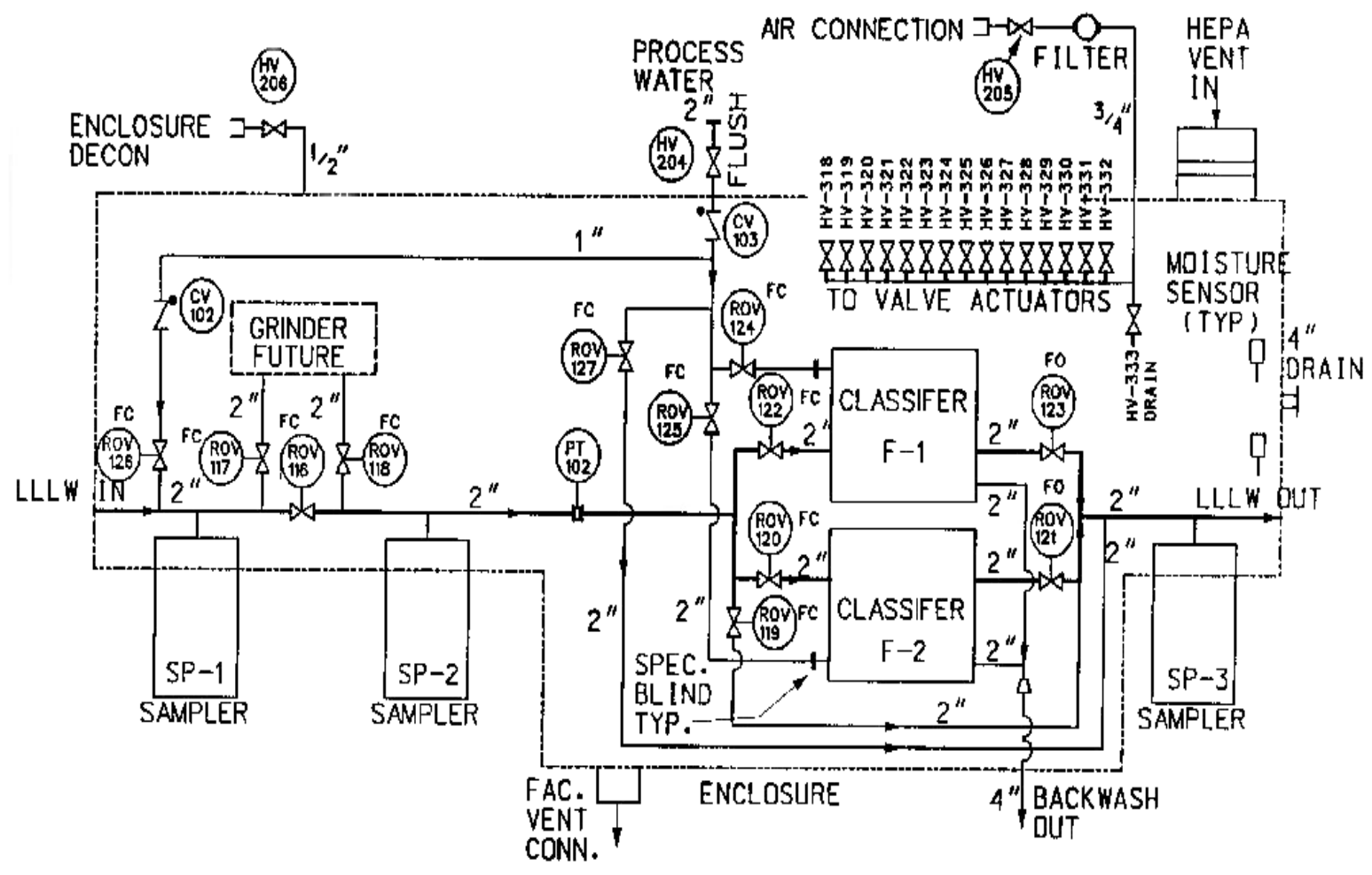

Fig. 4. Piping and Instrumentation Diagram for the PCS

The enclosure for the PCS is a one-of-a-kind, fabricated housing, which has been specifically designed for the GAAT application. A sampling system with three Bristol ${ }^{\mathrm{TM}}$ samplers is included to allow sampling of the feed slurry, the slurry after grinding, and the filtered slurry. Each sampler is accessed from outside the enclosure with interlocks prohibiting taking a sample with the sampler enclosure door open. Special supports and seals were fabricated to install these samplers.

The PCS will receive discharge from the WTP and is designed to filter out large solids $\geq 100 \mu \mathrm{m}$. The classifiers, manufactured by Orival, Inc., are installed in parallel so that either can serve as a backup if one is off-line. The classifiers can operate automatically to flush large solids back to tank W-9 while on-line based on either an operator selected time interval or a predetermined pressure drop across the classifier. The Iso-Lok in-line samplers, manufactured by Bristol Equipment Co., are located upstream and downstream of the classifiers. This arrangement accommodates sampling to verify filter performance. A spool piece was installed upstream of the classifiers to accommodate future installation of a grinder; however, as previously noted, a grinder will not likely be used in the SCS. An additional Iso-Lok sampler is installed upstream of the grinder location. Valving installed in the PCS will permit bypassing of the classifiers and/or the WaRTS pump, if necessary. 
Fig. 5 shows the PCS enclosure installed at the GAAT STF shortly after the PCS was delivered to ORNL. Double-contained piping was installed from the WTP discharge to the enclosure and from the PCS discharge to the SMTL enclosure. The classifier back-flush drain is also double contained to minimize the potential for a release of any hazardous material to the environment. System instrumentation and controls permit remote monitoring and operation of the samplers and valves from the GAAT operations control trailer.

Double-contained fittings were fabricated to attach field-routed piping to and from the enclosure. These fittings have performed satisfactorily.

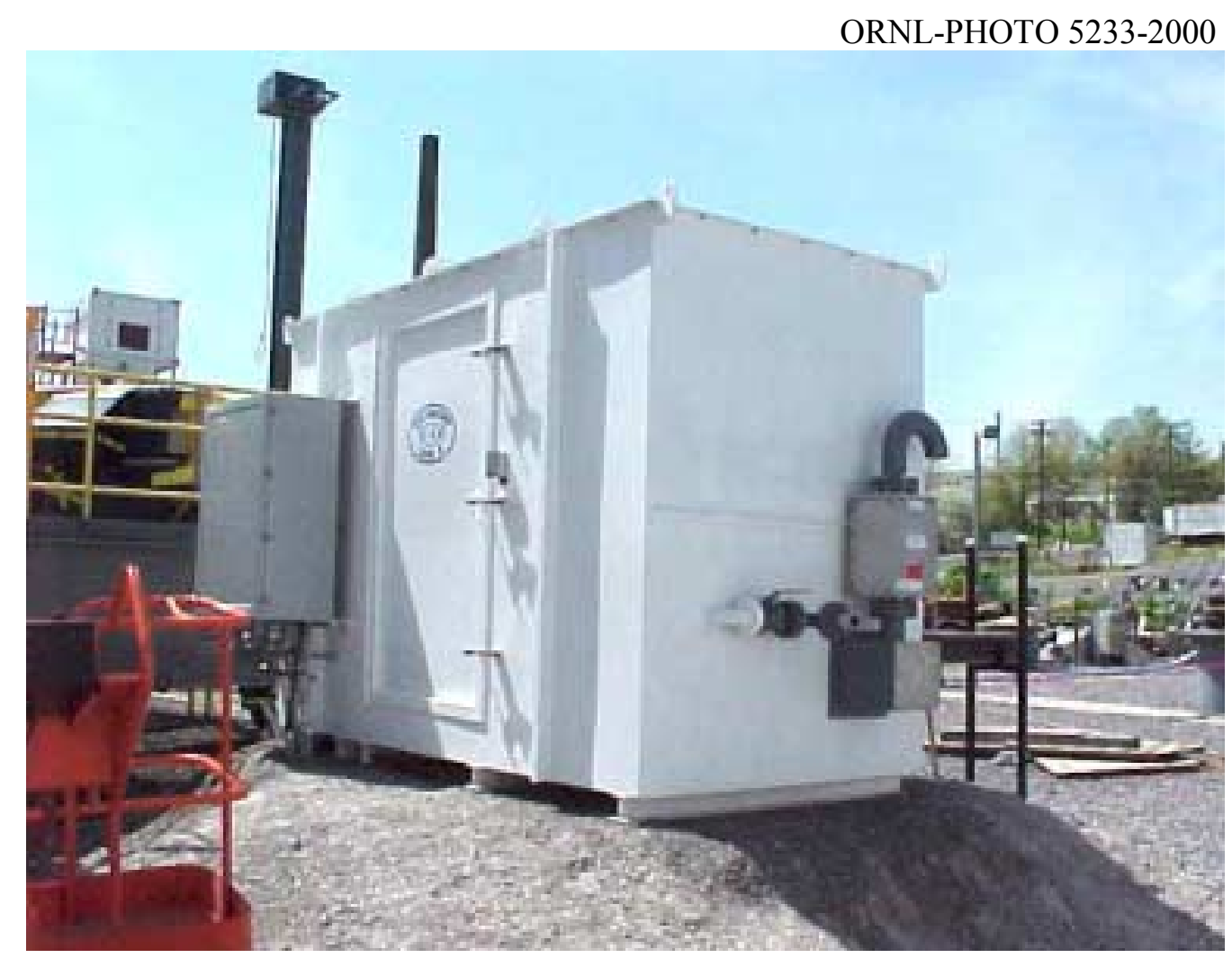

Fig. 5. PCS installed at the GAAT STF.

\subsection{VALVE BOX AND PIPING CONFIGURATION}

The process piping is 2 in-diam, Schedule 40, carbon-steel pipe. All joints are welded, except for connection points. All connection points are joined using 300-lb 4-bolt flanges. All process piping was hydrostatically tested to American Society for Mechanical Engineering (ASME) B31.3 Pipe and Piping Components requirements.

A new valve box was fabricated and installed adjacent to valve box 6 , which is located next to tank W-6 in the GAAT STF. The addition of a new valve box was necessary because of the high radiation levels measured in valve box 6 and space limitations in that box. The SCS valve box consists of three remotely operated ball valves (ROV) and three hand valves. The ROV may be configured for one of two possible operations: (a) return flow to tank W-9 or (b) direct flow to the 
MVST site or an auxiliary collection tank. Hand-operated valves are used to supply instrument air to the ROV.

A trailer-mounted water supply pump station is used to supply pressurized water to the PCS classifiers. The trailer is a standard, two-wheel, heavy-duty trailer. A hydraulically powered pump, a hydraulic fluid reservoir, an electric motor control panel, and a pan drain were added to the trailer to complete the pump station. The hydraulically powered pump will receive plant process water supply and, in turn, provide the necessary water supply to the SCS subsystems. A drawing of the SCS valve box and associated systems are presented in Fig. 6.

\subsection{WTP}

The WTP is comprised of a Discflo ${ }^{\mathrm{TM}}$, which is pump powered by a 125 -hp submersible motor, which is supported from a steel deployment mast, which is mounted on a structural platform above tank W-9. The design includes an adjustable mast and a confinement boundary for radioactive containment control and for maintaining negative pressure at the tank. A drawing of the WTP is shown as Fig. 7. Also, Fig. 8 is a photograph of the WTP during installation at tank W-9.

ORNL-DWG 2000-5331

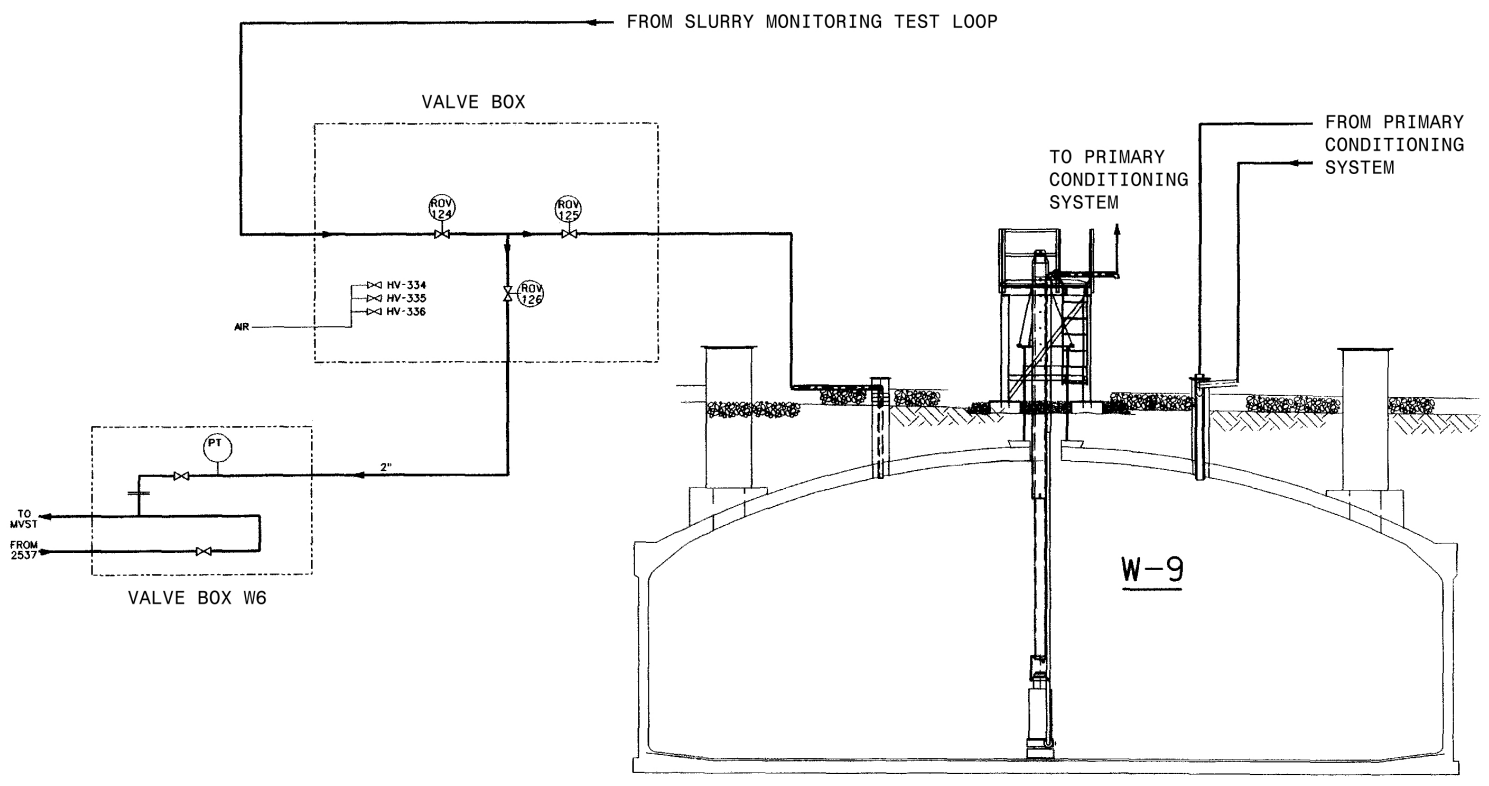

Fig. 6. Illustration of valve boxes showing the connectivity between W-9 and the SCS. 


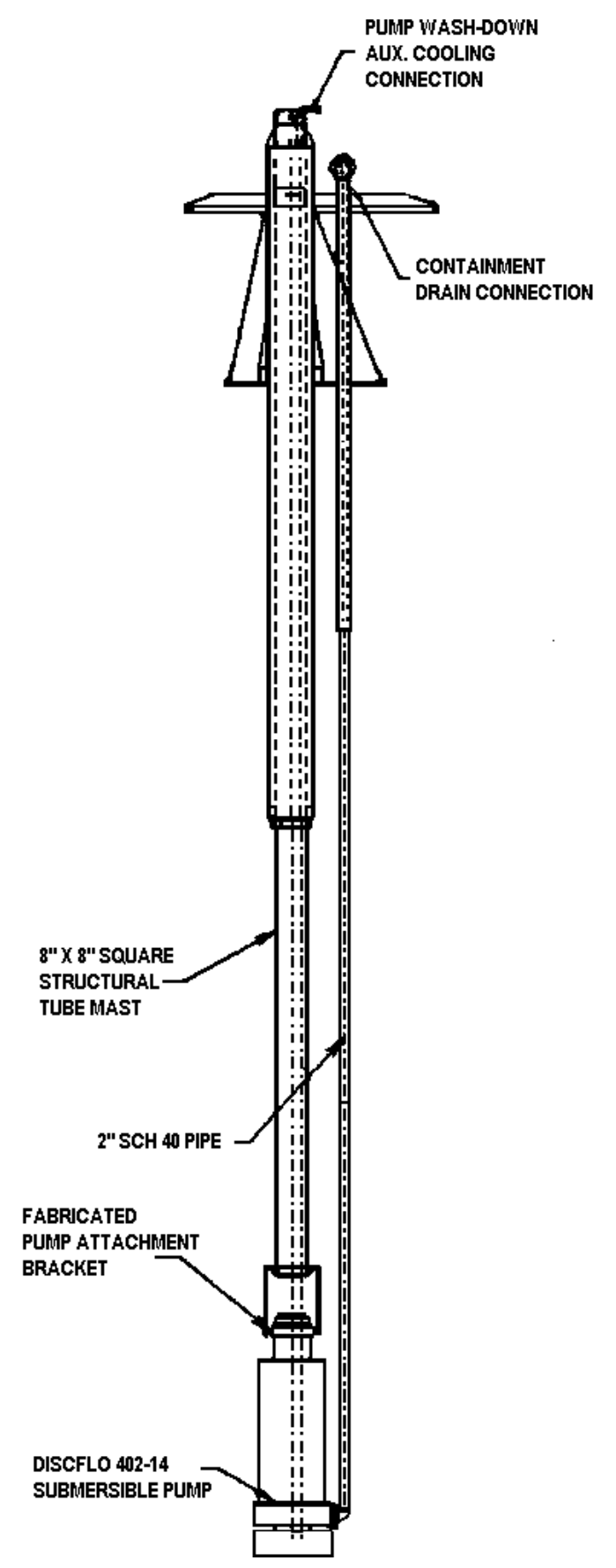

Fig. 7. WTP assembly drawing. 


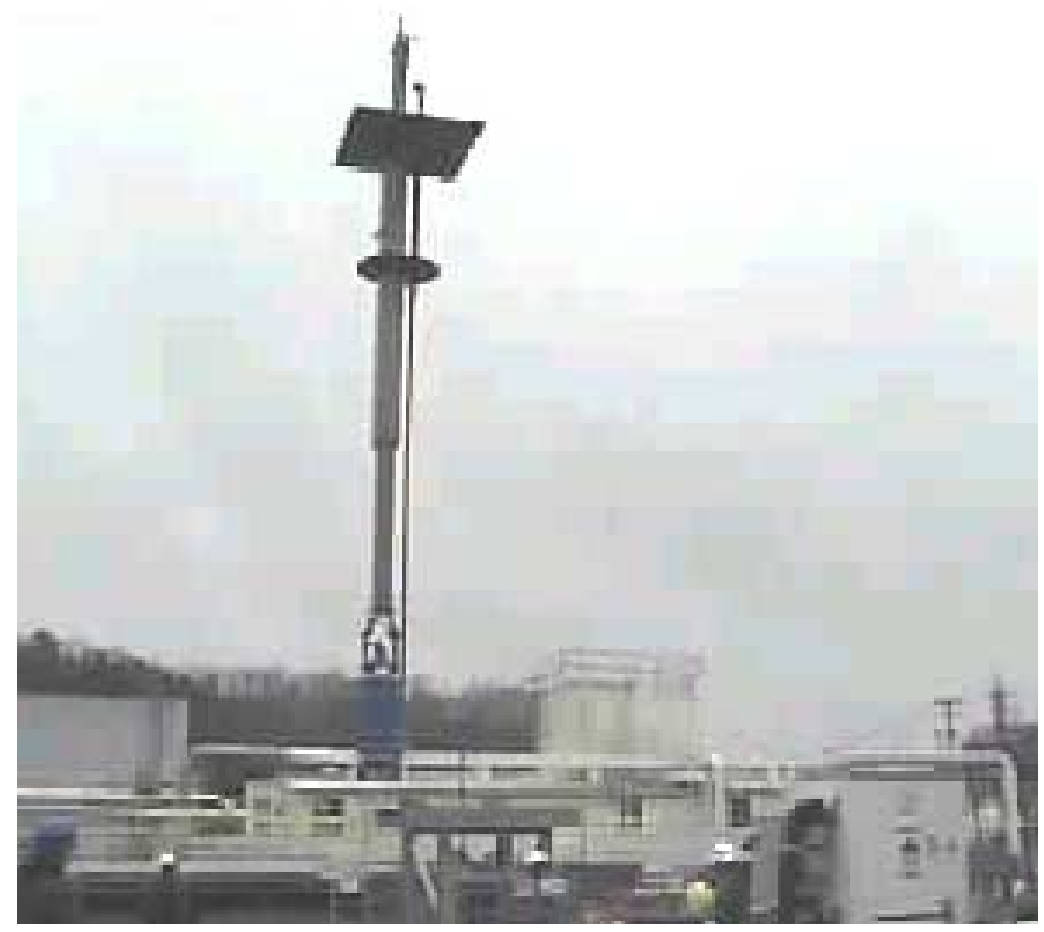

Fig. 8. Installation of the WTP in GAAT waste consolidation tank W-9.

\subsection{PAM}

The PAM system is comprised of three in-tank mixing assemblies, a controller, and necessary tank interface hardware. PulsAir System, Inc., manufactures and markets the PAM system. The mixing assemblies include four or five accumulator plates with one central plate; the remaining plates are located at the ends of folding arms. The arms also function to convey air from the air source to the accumulator plates. A sketch of the in-tank PAM configuration is shown as Fig. 9

Each PAM accumulator plate is deployed at a predetermined location along the bottom of the tank. In principal, the PAM uses timed pulses of compressed air to mix and suspend sludges and sediments into the tank supernatant. During operation, a pulse of compressed air is discharged through the accumulator plates, causing a large air bubble to form above the plate. Mixing is achieved as the low-pressure area under the bubble draws liquid back below it, while liquid above is forced up and away from the rising air bubble. As the bubble breaks at the surface, horizontal forces move the liquid to the tank walls, along which it travels to the tank bottom to complete the mixing cycle before the next pulse occurs.

The PAM was installed and placed in service at GAAT tank W-9 in June 1998 after a period of cold testing by and at the Robotics and Process Systems Division of ORNL. A view of one of the PAM assemblies before its installation into the GAAT is shown as Fig. 10. 


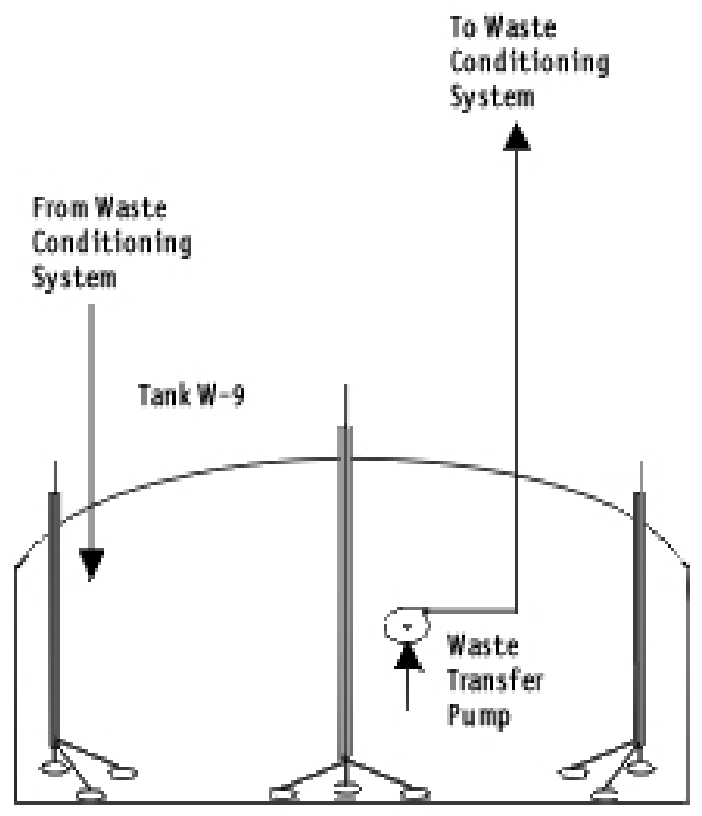

Fig. 9. PAM system configuration for GAAT tank W-9.

ORNL-PHOTO 5235-2000

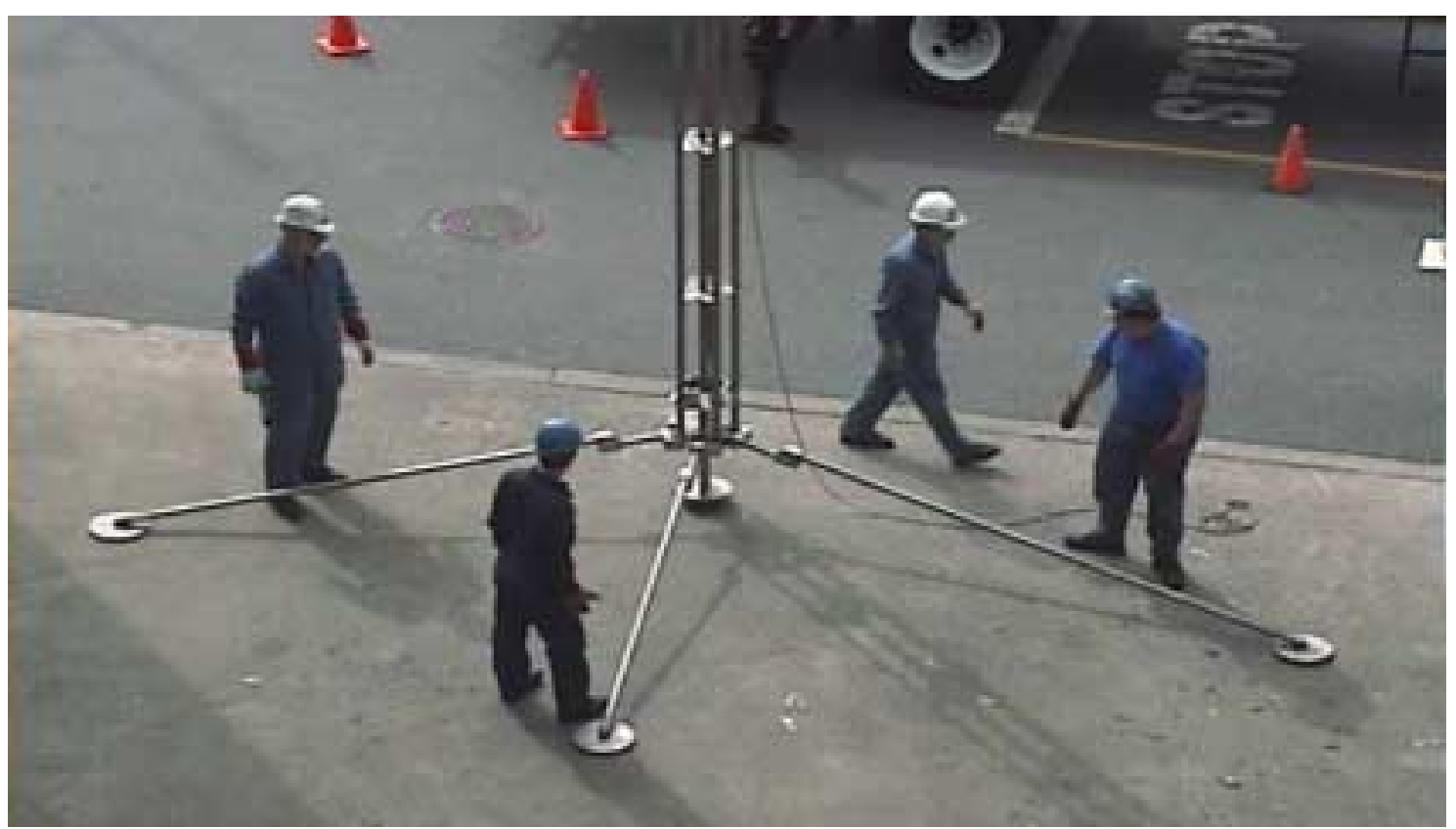

Fig. 10. PAM system before installation in GAAT tank W-9. 


\section{DESIGN AND FABRICATION}

\subsection{DESIGN}

Design of the SCS was performed by ORNL and LMES staff. Initially, ORNL conducted prototypic modeling and testing of the SMTL components ${ }^{1}$ to determine the size and type of equipment necessary to meet the design requirements. The scheduling of design and fabrication efforts was phased based on programmatic and project needs.

Instrument selection and preliminary design evaluation for the SMTL was conducted in FY 1997. Detailed design and fabrication of the SMTL was performed in FY 1998. Pacific Northwest National Laboratory supplied the PAM through a procurement contract with the University of Washington and PulsAir Systems, Inc., in FY 1998. Cold testing and subsequent installation of the PAM at GAAT Tank W-9 was completed in mid-FY 1998. Evaluation of WTP alternates and preparation of a design specification for the pump was prepared by LMES Engineering in FY 1998, and the pump and associated mast were procured near the end of FY 1998. The PCS design was conducted in FY 1998, and fabrication was completed in early FY 1999. The evaluation of PCS components and the detailed design and fabrication of the PCS piping and enclosure were initiated in FY 1998 and completed in FY 1999. Installation and initial hot operation of the integrated system were completed in FY 1999. Additional schedule information on the design and fabrication of the system is given in Table 1

Table 1. SCS schedule

\begin{tabular}{|c|l|c|l|}
\hline Item No. & \multicolumn{1}{|c|}{ Description } & Start date & \multicolumn{1}{|c|}{ Supplier } \\
\hline 1 & SMTL enclosure design & $12 / 97$ & LMES \\
\hline 2 & SMTL enclosure fabrication & $05 / 98$ & Alloy Fabrication Co. \\
\hline 3 & $\begin{array}{l}\text { SMTL enclosure installation and } \\
\text { testing }\end{array}$ & $08 / 98$ & ORNL \\
\hline 4 & $\begin{array}{l}\text { WTP design specification } \\
\text { (including mast) }\end{array}$ & $04 / 98$ & LMES \\
\hline 5 & WTP fabrication & $06 / 98$ & Discflo Corp. \\
\hline 6 & WTP installation and testing & $03 / 99$ & ORNL \\
\hline 7 & PCS enclosure design & $05 / 98$ & LMES \\
\hline 8 & PCS enclosure fabrication & $12 / 99$ & Alloy Fabrication Co. \\
\hline 9 & $\begin{array}{l}\text { PCS enclosure installation and } \\
\text { testing }\end{array}$ & $04 / 99$ & ORNL \\
\hline 10 & PAM system delivery & $04 / 98$ & PulsAir System, Inc. \\
\hline 11 & PAM system testing & $6 / 98$ & ORNL \\
\hline
\end{tabular}

\subsection{FABRICATION}

The SCS is comprised of both off-the-shelf components and specially designed equipmentwith the objective of using off-the-shelf components where readily available.

In March 1998, a contract was placed with Alloy Fabrication Company (AFC) to fabricate an SMTL from design drawings produced by LMES, Mechanical Systems and Process Design Engineering Department. The design allowed for a purchased prefabricated metal enclosure, as 
manufactured by Justrite Manufacturing Company, to be retrofitted to accept the piping, electrical, and instrument systems. The piping allows for the testing of up to four units concurrently or separately with proper valve lineup. The integral containment sump allows for the collection of drips and/or leaks and provides necessary piping to direct the contained liquid to the point of origination (tank W-9).

Early in the design of the system, it was noted that the SMTL enclosure had the potential for allowing a spray-type leak to compromise the door seal, as originally furnished with the enclosure. A design change was instituted to provide a 6-in.-wide neoprene strip along the side jambs, top header, and bottom threshold. The strip would direct sprays away from the door and to the sump. AFC fabricated the seal to provide a tight fit. Cold-test results indicated that the seal worked satisfactorily. However, it should be noted that the original enclosure door was not designed to be water tight as the enclosure was built for drum storage. The SMTL enclosure is fitted with a HEPA-filtered air inlet for ventilation and a louvered (fail close) outlet. Suction to the SMTL enclosure is provided from the waste consolidation tank (W-9) ventilation system. Lighting and heat for freeze protection are provided as well as a decontamination spray-down system.

Custom-designed, double-contained fittings were fabricated to attach field-routed piping to and from the enclosure, and each performed satisfactorily. Upon successful completion of acceptance testing by the vendor in July 1998, the SMTL was shipped to ORNL for installation at tank W-9.

The second system fabricated by AFC was the PCS, which was also designed by LMES. Lessons learned from the design and fabrication of the SMTL were applied in the design of the PCS. The fabrication contract was awarded in January 1999. This system allows for the rejection of solid particles with diameters greater than $100 \mu \mathrm{m}$. Provisions were made to add a grinder at a later date for particle-size reduction should that be required; however, analytical data from the analysis of sludge samples from tank W-9 revealed that the grinder is probably not required.

The design team decided to place structural supports on the exterior of the enclosure to allow a smooth interior surface for attaching supports, instruments, etc., as well as to have a smooth surface for decontamination, if required. A different approach was taken for the door and seal for the enclosure. The door on this enclosure shuts tightly against a steel-backing plate, which also has a rubber gasket. The exterior edge of the door includes toggle latches, which provide for a tight fit when the door is closed. An interlock switch was placed on the door so that the wastetransfer pump would run only when the door is shut. Upon successful completion of system testing at the vendor's shop in March 1999, the PCS was shipped to ORNL for installation at the STF tank W-9.

The valve box and associated piping components were off-the-shelf items and were procured through appropriate vendors. The assembly, including special piping connections, was performed by ORNL.

The pump and submersible motor assembly for the WTP were fabricated by Discflo Corporation in mid FY 1998 and delivered to ORNLin July 1998.

The PAM was fabricated by PulsAir Systems, Inc., and delivered to ORNL in March FY1998. 


\section{SCS EQUIPMENT AND FABRICATION COSTS}

The approximate cost for equipment and fabrication of the SCS are provided in Table 2. All the equipment has been has been procured and successfully deployed at the GAAT STF.

\section{ACCEPTANCE TESTING}

All subsystems were successfully tested at ORNL for functionality and performance according to design requirements, with the exception of the limited testing of the WTP performed by the vendor. However, it is duly noted that those tests performed by the vendor on the WTP met design requirements.

\section{CONCLUSIONS}

The SCS fabrication was completed, and the system was installed and successfully operated at the GAAT STF. The integrated SCS system (PCS, WTP, PAM, and SMTL) was placed in operation in May 1999. As of March 30, 2000, a total of 483,277 gal of slurry have been processed through the SCS and transferred to the MVSTs. Data collected from the SCS have continued to support the risk model used for the GAAT operation for determining cost, performance, and risk factors. It is anticipated that data collected from the GAAT effort will provide useful design information for applications at other DOE sites. 
Table 2. Summary of approximate equipment costs for the SCS

\begin{tabular}{|c|c|c|c|c|}
\hline $\begin{array}{l}\text { Item } \\
\text { No. }\end{array}$ & Assembly & Component & Cost $(\$)$ & Vendor/fabricator \\
\hline \multirow[t]{6}{*}{1} & \multicolumn{2}{|c|}{ SMTL enclosure } & 230,000 & \\
\hline & & $\begin{array}{l}\text { Enclosure assembly } \\
\text { including valves }\end{array}$ & 106,000 & $\begin{array}{c}\text { Alloy Fabrication Co., Clinton, } \\
\text { Tennessee }\end{array}$ \\
\hline & & Control system & 25,000 & $\begin{array}{c}\text { Real Time Products Corp. } \\
\text { (Intellution Software) } \\
\text { Pompano Beach, Florida }\end{array}$ \\
\hline & & Coriolis meter & 10,000 & $\begin{array}{c}\text { Endress + Hauser } \\
\text { Greenwood, Indiana }\end{array}$ \\
\hline & & Particle Size Analyzer & 85,000 & $\begin{array}{c}\text { Lasentec Inc. } \\
\text { Redmond, Washington }\end{array}$ \\
\hline & & $\begin{array}{c}\text { Ultrasonic Solids } \\
\text { Concentration Monitor }\end{array}$ & 4,000 & $\begin{array}{c}\text { Argonne National Laboratory } \\
\text { Argonne, Illinois }\end{array}$ \\
\hline \multirow[t]{4}{*}{2} & \multicolumn{2}{|r|}{ WTP } & 75,000 & \\
\hline & & $\begin{array}{l}\text { DiscFlo Pump and } \\
125-\mathrm{hp} \text { motor }\end{array}$ & 55,000 & DiscFlo Corp, El Cajon, California \\
\hline & & Mast & 16,000 & $\begin{array}{c}\text { Alloy Fabrication Co., Clinton, } \\
\text { Tennessee }\end{array}$ \\
\hline & & Flow meter & 4,000 & $\begin{array}{c}\text { Bailey Fischer \& Porter, Houston, } \\
\text { Texas }\end{array}$ \\
\hline \multirow[t]{6}{*}{3} & \multicolumn{2}{|c|}{ PCS enclosure } & 170,000 & \\
\hline & & Enclosure assembly & 98,000 & $\begin{array}{c}\text { Alloy Fabrication Co., Clinton, } \\
\text { Tennessee }\end{array}$ \\
\hline & & Valves & 13,000 & $\begin{array}{l}\text { Apollo Fabrications, Oliver } \\
\text { Springs, Tennessee }\end{array}$ \\
\hline & & Control system & 10,000 & $\begin{array}{c}\text { Oak Ridge National Laboratory, } \\
\text { Oak Ridge, Tennessee, and } \\
\text { Alloy Fabrication Co., Clinton, } \\
\text { Tennessee }\end{array}$ \\
\hline & & Solids classifiers & 9,000 & $\begin{array}{l}\text { Orival Inc., Englewood, New } \\
\text { Jersey }\end{array}$ \\
\hline & & Samplers & 40,000 & Bristol Eq. Co., Yorkville, Illinois \\
\hline \multirow[t]{4}{*}{4} & \multicolumn{2}{|c|}{ Transfer piping } & 78,000 & \\
\hline & & $\begin{array}{l}\text { Double-contained } \\
\text { piping }\end{array}$ & 45,000 & $\begin{array}{l}\text { Valley Pipe and Fitting Inc., } \\
\text { Powell, Tennessee }\end{array}$ \\
\hline & & Valves & 18,000 & $\begin{array}{l}\text { Cumberland Valve and Fittings } \\
\text { Inc., Knoxville, Tennessee }\end{array}$ \\
\hline & & Valve boxes & 15,000 & $\begin{array}{l}\text { Apollo Fabrication Co., Oliver } \\
\text { Springs, Tennessee }\end{array}$ \\
\hline \multirow[t]{3}{*}{5} & \multicolumn{2}{|c|}{ Mixer system } & 145,000 & \\
\hline & & $\begin{array}{c}\text { PAM deployment } \\
\text { system }\end{array}$ & 120,000 & $\begin{array}{c}\text { Applied Physics Laboratory } \\
\text { University of Washington, } \\
\text { Seattle }\end{array}$ \\
\hline & & Control system & 25,000 & $\begin{array}{l}\text { PulsAir, Inc., Bellevue, } \\
\text { Washington }\end{array}$ \\
\hline \multicolumn{3}{|c|}{ Approximate total system cost } & 698,000 & \\
\hline
\end{tabular}




\section{REFERENCES}

1 T. D. Hylton et. al., Testing of In-Line Slurry Monitors and PulsAir Mixers with Radioactive Slurries, ORNL/TM-1999/111, Lockheed Martin Energy Research Corp., Oak Ridge National Laboratory, Oak Ridge, Tennessee, June, 1999. 
ORNL/TM-2000/222

\section{INTERNAL DISTRIBUTION}

1. J. N. Herndon-Record Copy

2. B. E. Lewis

3. ORNL Central Research Library

4. ORNL Laboratory Records

5. K. E. Plummer

6. J. D. Randolph

7. S. D. Van Hoesen

\section{EXTERNAL DISTRIBUTION}

8. D. H. Bolling, Bechtel Jacobs Company, P. O. Box 2008, MS 6402, Oak Ridge, TN 37831.

9. J. R. Farmer, Lockheed Martin Energy Systems, P. O. Box 2009, MS-8031, Oak Ridge, TN 37831.

10. M. A. Johnson, Tetra-Tech Inc., Oak Ridge National Laboratory, Oak Ridge, TN 37831.

11. J. R. Noble-Dial, U.S. Department of Energy, Oak Ridge Operations Office, P. O. Box 2009, Oak Ridge, TN 37831

12. Office of Scientific and Technical Information, DOE Oak Ridge Field Office, P. O. Box 62, Oak Ridge, TN 37831

13. T. P. Pietrok, U.S. Department of Energy, Richland Operations Office, P. O. Box 550, MS K8-50, Richland, WA 99352

14. B. J. Williams, Pacific Northwest National Laboratory, P. O. Box 999, MSIN K9-69, Richland, WA 99352 